\title{
SARS-Cov-2 Lockdown Mediates Increased Use of Technology for Leisure: Implication for Development of Digital Hygiene
}

\author{
Manoj Kumar Sharma ${ }^{1}$; Nitin Anand ${ }^{1}$; A Thirumoorthy ${ }^{2}$; Pranjali Chakraborty Thakuri; Priya Singh ${ }^{1}$; Ajith SJ'; Jayesh Suresh \\ Kande'; Keshava D Murthy'; Thamarai Manalan $S^{2}$; Neeraj MS'; Ripudamn Singh $^{2}$ \\ ${ }^{1}$ SHUT clinic (Service for Healthy Use of Technology), Department of Clinical Psychology, National Institute of Mental Health \& \\ Neuro Sciences (NIMHANS), Bangalore, Karnataka, India. \\ ${ }^{2}$ Department of Psychiatric Social Work, National Institute of Mental Health \& Neuro Sciences (NIMHANS), Bangalore, Karnataka, \\ India.
}

\author{
*Corresponding Author(s): Manoj Kumar Sharma \\ Professor, Department of Clinical Psychology, SHUT \\ clinic (Service for Healthy Use of Technology) NIM- \\ HANS, Bengaluru, India. \\ Tel: +9108026995197; Fax: 0910802652121 \\ Email: shutclinic@gmail.com
}

Received: Nov 23, 2020

Accepted: Dec 21, 2020

Published Online: Dec 24, 2020

Journal: Journal of Addiction and Recovery

Publisher: MedDocs Publishers LLC

Online edition: http://meddocsonline.org/

Copyright: (C) Sharma MK (2020). This Article is distributed under the terms of Creative Commons Attribution 4.0 International License

Keywords: SARS-CoV-2; Loneliness; Leisure; Digital activities; Digital hygiene.

\section{Introduction}

The digital technologies are influencing the nature of the home-based leisure activities. It changed the opportunities for leisure activities and become the default way of how engagement in leisure activities is occurring [1,2]. The home-based digital leisure activities offer the choice of technology to use, choose the person with whom one wants interact and allow

\section{Abstract}

Digital activities has become the preferred modality to structure leisure time during SARS-Cov-2. It has led to increased use of digital technologies. Mr. A, 23 years old, unmarried male pursuing post-graduation belonging to a nuclear family contacted for management of excessive use of online technologies during the SARS-CoV-2 related lock down period. The clinical interview technique was used for assessing the pattern and dysfunctions related to use of technologies. The case demonstrates the role of online activities like social media, online entertainment, and online gaming to cope with absence of access to offline leisure time activities during the SARS-CoV-2 lockdown. However, there is a need to create awareness that engagement in online leisure time activities can lead to excessive use of online activities in the absence of avenues for engagement in offline activities. people living in the same household to have different leisure experiences in privacy. The digital technology-mediated activities enable the individuals to develop non-shared or individual digital leisure activities. It may be in the form of video chat, social media interactions, online entertainment shows, movies, online gaming, online gambling, and the like. In the ongoing 
SARS-CoV-2 pandemic, millions worldwide are experiencing a sudden change in their daily work and leisure routine. To follow the SARS-CoV-2 related lockdown norms in many countries, most individuals are working from home. This has caused an immense increase in the internet usage in the population which primarily used it to access news or information or online entertainment. But now use it for all work and leisure activities. Digital technology is now used extensively for virtual office meetings, connecting with family members, friends, for online entertainment and leisure tasks.

The available literature indicates that SARS-CoV-2 pandemic guided lockdown has led to increased use of digital technologies in the Indian context. As per available reports, there has been an average increase of $30 \%$ in internet-based technologies for completion of work and leisure activities during the lockdown period in India. Besides, the Silicon Valley of India, namely Bangalore, has witnessed the cellular network data consumption increase by $70 \%$ since the onset of lockdown [3]. Social media usage increased from 0.4 million in January 2020 to 20.3 million by $24^{\text {th }}$ March 2020 [4]. The Social media has seen a $42 \%$ increase with an overall time spent increased to 274 minutes per week, whereas the time spent on use of chat services has increased by $43 \%$ to, 322 minutes per week [5]. Similarly, a $39 \%$ increase in download of games has been witnessed along with $44 \%$ increase in the time spent on online gaming. The number of gaming sessions has also increased from 5 to 7 sessions, with session duration increased to around 45 minutes from the earlier 30 minutes [5-7]. The online streaming of online video series viewed over smartphones has also shown an increase of $32 \%$ in its consumption in online entertainment category whereas a $52 \%$ increase was noted on time spent on watching movies over smartphones [7]. Thus, life in current times of SARS-CoV-2 pandemic and related lockdown revolves significantly around the use of technology and digital platforms for all aspects of life. It appears to be increasing challenges for the population in maintaining balance between the time spent on online and offline activities. The present case contacted the tertiary specialty clinic Service for Healthy Use of Technology (SHUT) for management of excessive use of online technologies during the SARSCoV-2 related lockdown period.

\section{Case report}

Mr. A, 23 years old, unmarried male pursuing post-graduation, belonging to a nuclear family with no family history, suggests of mental health difficulties, reported to the SHUT clinic. Premorbid history indicates him to be an extrovert. He presented with a 3 weeks history indicating increased use of social media, online entertainment, online gaming, inability to complete his academic assignments, and irritability. His online use pattern indicated that before the start of the COVID-19 lockdown, he spent 3 to 4 hours each day on the mobile in the evening. The time spent online was primarily for social media networking, chatting, messaging, gaming, listening to music and watching online shows and movies. Before the SARS-CoV-2 pandemic related lockdown, these online behaviors did not affect his studies, engagement in offline physical activities, and interaction with family members. However, during COVID-19 related lockdown, his online usage pattern gradually became excessive over a period of three weeks. He started spending more time on social media, video chatting, messaging, and increased in number of sessions for playing online games. There was also an increase in watching online streaming series. He was watching a minimum of two movies or three-four episodes of streaming web shows per day. His usage pattern increased from 3 to 4 hours to 8 to 10 hours per day during the COVID-19 related lockdown. He experienced frequent dryness of eyes and decreased sleep. The increase in the use of online activities also led to a delay in initiation of sleep by 2 to 3 hours, and the presence of drowsiness and lethargy on a subsequent day. His engagement in physical activities decreased. The procrastination increased for academic and other offline activities. These aspects and increased time spent on online activities contributed to increases in interpersonal stress among the members of the family. He reportedly missed a deadline for submission of an online academic assignment.

He attributed the increase in online activities to an unstructured daily schedule for biological, social and academic tasks, the absence of non-addictive online technologies, and the sudden unavailability of offline modalities to have an enjoyable leisure time. The availability of offers for various online activities and increase in procrastination due to free time availability were also indicated to be factors that affected the desire to continue or to reduce the ability to log out from online activities. Besides, he was engaging in frequent rationalization like "I should enjoy now as the lockdown will end soon", "I can complete all academic tasks at the end of lockdown", I deserve this enjoyment as I usually work hard for academics", or "There is still lot of time for the lockdown to end, I will complete my academic tasks before it ends" which also contributed in maintaining his increased usage of online activities. These rationalizations also minimized his willingness to curtail his excessive online use as well. The family members also became critical about this excessive online use. To deal with these unpleasant emotions caused by their unkind and critical remarks, he further increased his engagement in social media and online entertainment as a way to regulate and enhance his mood. He attempted few changes in his online usage pattern for a few days i.e. by limiting smartphone usages to certain hours, engaging in indoor offline leisure activities and spending time with family members. However, after 3 to 4 days of his effort, he still reported craving for online activities and attributed it to lack of novelty in the available offline leisure time activities.

\section{Discussion}

This case demonstrates the role of online activities like social media, online entertainment, and online gaming as a method to cope with the absence of access to offline leisure time activities during the COVID-19 lockdown. Studies have shown that if leisure time is not optimally arousing, it can be experienced as boredom [8]. Lack of engagement in meaningful activities to overcome boredom has been further linked to consequences such as psychological distress, addiction and increased use of mobile phone or internet, and social networking [9]. Also, psychological distress like depression has been found to have a stable correlation with problematic internet use in studies conducted among young adults in India [9-12]. Also, once an individual becomes engaged in heavy use of online activities, they are known to have a declining preference to engage in offline leisure activities like sports, exercise [13].

Keeping into account the above findings, we can comprehend that in this case, the problematic use of online entertainment, social media appears to have been initiated through a coping pathway to overcome boredom, loneliness, lack of inperson social interactions, lack of novelty, psychological distress or through relationship pathway as a modality to satisfy needs of affiliation, affection, validation of thoughts, emotions and 
reassurance or its combination as well during the COVID-19 lockdown. However, with a gradual lapse of time, it would have activated the internet addiction pathway where the individual experiences craving for online use, loss of control over use, strong urges to use despite unpleasant consequences. Thus, a number of these pathways likely play a role in initiating and maintening of problematic online use. A number of these pathways leading to dysfunctional use of internet have been proposed by Billieux [14].

Thus, the use of online technology in times of COVID-19 lockdown has helped in the near seamless transition from offline networks to digital interface for continuing with work commitments, social communication, information seeking, and for fulfillment of leisure activities. However, there is a need to create awareness that engagement in online leisure time activities is used to overcome boredom, loneliness, psychological distress or fulfill the psychological needs of affection, affiliation and validation. However, there is a need to create awareness that engagement in online leisure time activities can lead to excessive or addictive use of online activities in the absence of avenues for engagement in offline activities. Therefore, in the times of COVID-19, digital hygiene is crucial in maintaining the healthy use of technology. Digital hygiene suggests that individual are to maintain consistent patterns for sleep - wake schedules, meal timings, daily online work structure, online leisure activities, online and offline family time/rituals, and optimal engagement in exercise routines to ensure healthy use of technology which can help in overcoming boredom, loneliness and psychological distress especially during the challenging times of COVID-19.

\section{Acknowledgement}

ICMR DHR Delhi, Delhi, India awarded the grant to Dr Manoj Kumar Sharma.

Compliance with ethical standard: There was no conflict of interest in relation to present work as well as informed consent of the human subjects had been taken prior to inclusion in the study.

Conflict of interest: Authors of the paper did not have any conflict of interest.

Statement of Human right: The studies have been approved by the Institutional and/or national research ethics committee .

Research involving Human Participants and/or Animals: All procedures performed in studies involving human participants were in accordance with the ethical standards of the institutional and/or national research committee and with the 1964 Helsinki declaration and its later amendments or comparable ethical standards.

\section{References}

1. Gershuny J. Web Use and Net Nerds: A Neofunctionalist Analysis of the Impact of Information Technology in the Home. Soc Forces. 2003; 82: 141-168.

2. Sintas JL, De Francisco LR, Álvarez EG. The nature of leisure revisited: An interpretation of digital leisure. J Leis Res. 2015; 47: 79-101.

3. Sengupta D. lockdown: As India connects to stay connected, net loses its zip - The Economic Times [Internet]. The Economic Times. 2020.

4. Balram S. Covid-19 Impact: Social media activity in the country grew 50X in early March, says Nielsen - The Economic Times [Internet]. The Economic Times. 2020.

5. Gaurav Laghate. Mobile consumption jumps $12 \%$; social media, news, video streaming biggest gainers - The Economic Times. The Economic Times. 2020.

6. PARTNER BI. Mobile games download witnesses $39 \%$ surge during Covid-19 lockdown | Business Insider India [Internet]. Bussiness Insider India. 2020.

7. NV V. BARC India \& Nielsen Media explain the crisis consumption impact of COVID -19 on TV \& smartphone behaviour across India Broadcast \& Cablesat. Broadcast \& Cablesat. 2020.

8. Iso-Ahola SE, Weissinger E. Leisure and Boredom. J Soc Clin Psychol [Internet]. 1987; 5: 356-364.

9. $\mathrm{Lin} \mathrm{CH}$, Lin $\mathrm{SL}, \mathrm{Wu} \mathrm{CP}$. The effects of parental monitoring and leisure boredom on adolescents' internet addiction. Adolescence. 2009.

10. Anand N, Jain P, Prabhu S, Thomas C, Bhat A, Prathyusha P, et al. Prevalence of excessive internet use and its association with psychological distress among university students in South India. Ind Psychiatry J. 2018.

11. Anand N, Jain P, Prabhu S, Thomas C, Bhat A, Prathyusha P, et al. Internet use patterns, internet addiction, and psychological distress among engineering university students: A study from India. Indian J Psychol Med. 2018.

12. Anand N, Thomas C, Jain PA, Bhat A, Thomas C, Prathyusha P $V$., et al. Internet use behaviors, internet addiction and psychological distress among medical college students: A multi centre study from South India. Asian J Psychiatr. 2018.

13. Zhou R, Fong PSW, Tan P. Internet use and its impact on engagement in leisure activities in china. Votruba SB, editor. PLoS One. 2014.

14. Billieux J. Problematic Use of the Mobile Phone: A Literature Review and a Pathways Model. Curr Psychiatry Rev. 2012. 